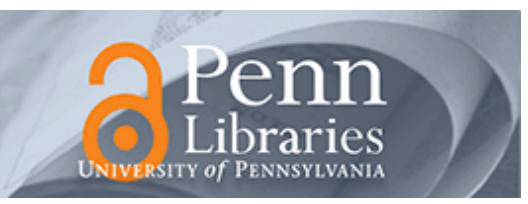

University of Pennsylvania

ScholarlyCommons

December 2006

\title{
Piezoelectric Aluminum Nitride Vibrating Contour-Mode MEMS Resonators
}

\author{
Gianluca Piazza \\ University of Pennsylvania, piazza@seas.upenn.edu \\ Philip J. Stephanou \\ University of California \\ Albert P. Pisano \\ University of California
}

Follow this and additional works at: https://repository.upenn.edu/ese_papers

\section{Recommended Citation \\ Gianluca Piazza, Philip J. Stephanou, and Albert P. Pisano, "Piezoelectric Aluminum Nitride Vibrating Contour-Mode MEMS Resonators", . December 2006.}

Copyright 2006 IEEE. Reprinted from Journal of Microelectrochemical Systems, Volume 15, Issue 6, December 2006, pages 1406-1418.

This material is posted here with permission of the IEEE. Such permission of the IEEE does not in any way imply IEEE endorsement of any of the University of Pennsylvania's products or services. Internal or personal use of this material is permitted. However, permission to reprint/republish this material for advertising or promotional purposes or for creating new collective works for resale or redistribution must be obtained from the IEEE by writing to pubs-permissions@ieee.org. By choosing to view this document, you agree to all provisions of the copyright laws protecting it.

This paper is posted at ScholarlyCommons. https://repository.upenn.edu/ese_papers/223

For more information, please contact repository@pobox.upenn.edu. 


\title{
Piezoelectric Aluminum Nitride Vibrating Contour-Mode MEMS Resonators
}

\begin{abstract}
This paper reports theoretical analysis and experimental results on a new class of rectangular plate and ring-shaped contour-mode piezoelectric aluminum nitride radio-frequency microelectromechanical systems resonators that span a frequency range from 19 to $656 \mathrm{MHz}$ showing high-quality factors in air $\left(Q_{\max }=4300\right.$ at $229.9 \mathrm{MHz}$ ), low motional resistance (ranging from 50 to $700 \Omega$ ), and center frequencies that are lithographically defined. These resonators achieve the lowest value of motional resistance ever reported for contour-mode resonators and combine it with high $\mathrm{Q}$ factors, therefore enabling the fabrication of arrays of high-performance microresonators with different frequencies on a single chip. Uncompensated temperature coefficients of frequency of approximately $25 \mathrm{ppm} /{ }^{\circ} \mathrm{C}$ were also recorded for these resonators. Initial discussions on mass loading mechanisms induced by metal electrodes and energy loss phenomenon are provided.
\end{abstract}

\section{Keywords}

Aluminum nitride, contour-mode resonators, microelectromechanical systems (MEMS) resonators, piezoelectric resonators, radio-frequency (RF) MEMS

\section{Comments}

Copyright 2006 IEEE. Reprinted from Journal of Microelectrochemical Systems, Volume 15, Issue 6, December 2006, pages 1406-1418.

This material is posted here with permission of the IEEE. Such permission of the IEEE does not in any way imply IEEE endorsement of any of the University of Pennsylvania's products or services. Internal or personal use of this material is permitted. However, permission to reprint/republish this material for advertising or promotional purposes or for creating new collective works for resale or redistribution must be obtained from the IEEE by writing to pubs-permissions@ieee.org. By choosing to view this document, you agree to all provisions of the copyright laws protecting it. 


\title{
Piezoelectric Aluminum Nitride Vibrating Contour-Mode MEMS Resonators
}

\author{
Gianluca Piazza, Member, IEEE, Philip J. Stephanou, Member, IEEE, and Albert P. (Al)Pisano
}

\begin{abstract}
This paper reports theoretical analysis and experimental results on a new class of rectangular plate and ring-shaped contour-mode piezoelectric aluminum nitride radio-frequency microelectromechanical systems resonators that span a frequency range from 19 to $656 \mathrm{MHz}$ showing high-quality factors in air $\left(Q_{\max }=4300\right.$ at $\left.229.9 \mathrm{MHz}\right)$, low motional resistance (ranging from 50 to $700 \Omega$ ), and center frequencies that are lithographically defined. These resonators achieve the lowest value of motional resistance ever reported for contour-mode resonators and combine it with high $Q$ factors, therefore enabling the fabrication of arrays of high-performance microresonators with different frequencies on a single chip. Uncompensated temperature coefficients of frequency of approximately $-25 \mathrm{ppm} /{ }^{\circ} \mathrm{C}$ were also recorded for these resonators. Initial discussions on mass loading mechanisms induced by metal electrodes and energy loss phenomenon are provided.

[2006-0019]
\end{abstract}

Index Terms-Aluminum nitride, contour-mode resonators, microelectromechanical systems (MEMS) resonators, piezoelectric resonators, radio-frequency (RF) MEMS.

\section{INTRODUCTION}

$\mathbf{T}$ HE demand of consumer electronics for radio-frequency (RF) filters and frequency reference elements has focused attention on the reduction of size, power consumption, and price and pushed current research interests towards the manufacturing of a single-chip integrated RF solution. Vibrating contour-mode microelectromechanical system (MEMS) resonators constitute a very promising technology for ultimately realizing this vision.

Several electrostatically transduced micromechanical resonators have been demonstrated in the very-high- and ultra-high-frequency spectra [1]-[4]; despite their sheer high $\mathrm{Q}$ on the order of 10000 , they exhibit large values of motional resistance (hundreds of $\mathrm{k} \Omega$ ), which ultimately complicates the interfacing of these electrostatic devices to $50 \Omega$ RF systems. The low electromechanical coupling coefficient of the surface-based electrostatic transduction mechanism cannot be sufficiently improved without introducing ultrasmall air gaps (less than $20 \mathrm{~nm}$ ) in the fabrication process. Furthermore, recent efforts [5]-[8] trying to act on geometrical parameters, such as the effective actuation area, in order to reduce the equivalent

Manuscript received February 13, 2006; revised July 8, 2006. This work was supported by CSAC-DARPA under Grant NBCH1020005. Subject Editor S. Lucyszyn.

G. Piazza is with the Department of Electrical and Systems Engineering, University of Pennsylvania, Philadelphia, PA 19104 USA.

P. J. Stephanou and A. P. Pisano are with the Department of Mechanical Engineering, University of California, Berkeley, CA 94720 USA.

Color versions of Figs. 1-4, 6, 7, 12, 14, and 15 are available online at http:// ieeexplore.ieee.org.

Digital Object Identifier 10.1109/JMEMS.2006.886012 motional resistance have not shown very significant improvements. Recently proposed "internal" electrostatic transduction [9], [10] represents a potential method for reducing the motional resistance of these resonators, but it is still an unproven technology and suffers from the need of large bias voltages that ultimately limit the reliability of ultrathin layers of high-K dielectrics and intrinsic large capacitance values that mask the resonator response at high frequencies.

Piezoelectric materials such as aluminum nitride or quartz inherently offer order of magnitude larger electromechanical coupling coefficients. Body forces produced by thin piezoelectric elements have been successfully exploited in surface acoustic wave (SAW) devices [11], film bulk acoustic wave resonators (FBARs) [12], and shear-mode quartz resonators [13], achieving gigahertz frequencies and demonstrating high Q factors. Despite being a proven technology, SAW devices do not scale well to RF applications due to the resulting need for submicrometer lithography and decreasing power handling capabilities. Moreover, FBARs and shear-mode quartz resonators do not permit economical manufacturing of a single-chip RF module because multiple frequencyselective arrays of piezoelectric resonators cannot be easily fabricated on the same substrate since film thickness determines the frequency.

This paper introduces a new class of aluminum nitride piezoelectric resonators that have their fundamental frequency defined by in-plane dimensions, which are prescribed at the computer-aided design (CAD) layout level. For this reason the devices are called contour-mode resonators. The use of contour modes (with frequencies determined by in-plane dimensions and not film thickness as for FBARs or shear quartz resonators) permits the batch fabrication of arrays of piezoelectric microresonators with different frequencies on a single chip. These devices, realized in the shape of plates or rings, uniquely combine multiple frequencies with the ability to interface directly with $50 \Omega$ systems (by means of a low motional resistance generally varying between 50 and $700 \Omega$ ) and achieve high quality factors (as high as 4300 at $230 \mathrm{MHz}$ ) in air. The next sections will focus on the electromechanical analysis of these resonators, the techniques used for their fabrication, and their electrical performance and offer discussions on the temperature dependence and mass sensitivity of their center frequency and energy loss mechanisms.

\section{Design of Rectangular Plate Resonators}

Fig. 1 shows a schematic diagram of an AlN contour-mode resonators shaped as a rectangular plate. The resonator is made out of an AlN body sandwiched between a bottom Pt electrode and a top Al electrode. A vertical electric field applied across the film thickness induces in plane dilation of the structure 


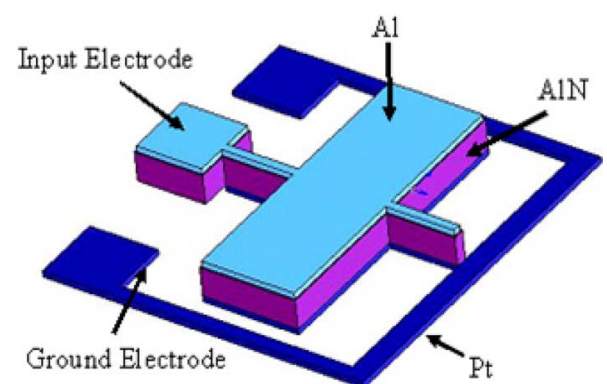

Fig. 1. Schematic representation of one-port AlN contour-mode rectangular plate resonator.

through the $d_{31}$ coefficient and excites the resonator either in length-extensional or width-extensional mode shapes, depending on whether the structure vibrates primarily across its length or width and the excitation frequency. The equivalent electromechanical model of the resonator is derived. First frequency equation and mode shapes are given, and then the equivalent parameters are computed using an energy method based on Mason's derivation [14]. As will be shown, the analysis of the most important mode shapes for the rectangular plate can be simplified to the one-dimensional case of a bar vibrating across either its length or width.

The problem of in-plane vibrations of plates has been solved in many different ways in the past [15], [16]. It is very complicated to obtain exact closed-form solutions; an approximate solution that gives the frequency equation and mode shape is reported in [14]

$$
\frac{\cot \left(\alpha \frac{W}{2}\right)}{\cot \left(\beta \frac{W}{2}\right)}=\frac{-2 \alpha \beta k^{2}(1-\sigma)}{\left(\beta^{2}-k^{2}\right)\left(\alpha^{2}+\sigma k^{2}\right)}
$$

where

$$
\begin{array}{rlrl}
\alpha^{2} & =\frac{(1-\sigma) \theta^{2}}{2}-k^{2} & \theta^{2} & =\frac{2 \rho \omega^{2}(1+\sigma)}{E_{P}} \\
\beta^{2} & =\theta^{2}-k^{2} & k & =n \frac{\pi}{L}
\end{array}
$$

and

$$
\begin{aligned}
& u_{x}=A\left(\cos (\alpha y)+\frac{B}{A} \cos (\beta y)\right) \cos (k x) \\
& u_{y}=A\left(-\frac{\alpha}{k} \sin (\alpha y)+\frac{B k}{A \beta} \sin (\beta y)\right) \sin (k x)
\end{aligned}
$$

where

$$
\frac{B}{A}=\frac{-2 \alpha \beta \sin \left(\frac{\alpha W}{2}\right)}{\left(\beta^{2}-k^{2}\right) \sin \left(\frac{\beta W}{2}\right)}
$$

and $W$ is the width of the resonator, $L$ its length, $n$ the mode number, and $\sigma$ and $E_{P}$ the in-plane Poisson's ratio and equivalent Young's modulus of AlN. An equivalent Young's modulus was introduced for AlN. This is justified by the in-plane symmetry of highly $c$-axis oriented AlN films as in the case of this paper. $x$ and $y$ are the coordinate of the system with $x$ parallel to the length and $y$ parallel to the width of the plate; $u_{x}$ and $u_{y}$ represent the displacement, respectively, in the $x$ and $y$ directions.

Several modes of vibrations can be found in the rectangular plate either by changing the mode number $n$ or by exchanging the dimension of length with width (and therefore looking at width-extensional mode shapes). Only few (Fig. 2) of these modes of vibration can be electrically detected [15]. Their detection depends on both the strength of the electromechanical coupling associated with the particular mode and the quality factor of the mechanical structure. Intuitively, just those mode shapes that undergo a net area change over the whole electroded surface generate a net motional current and can be detected electrically. Analytically, the electromechanical coupling $\eta$ takes this effect into account and can be approximately computed as

$$
\eta=\frac{Q_{\mathrm{TOT}}}{u_{\mathrm{MAX}}}=\frac{\frac{2 E_{P}}{1-\sigma} d_{31} \iint_{A}\left(\frac{\partial u_{x}}{\partial x}+\frac{\partial u_{y}}{\partial y}\right) d A}{u_{\mathrm{MAX}}} \approx 2 E_{P} d_{31} W
$$

where $Q_{\mathrm{TOT}}$ is the total charge stored on one electrode, $u_{\mathrm{MAX}}$ the maximum displacements the structure undergoes at the location for which the equivalent parameters are computed, $d_{31}$ the piezoelectric coefficient, $u_{x}$ and $u_{y}$ the displacement, respectively, in the $x$ and $y$ directions, and $A$ is the electroded area of the resonator. The rest of the symbols were defined in (1)-(4). This value applies for the length-extensional mode shown in Fig. 2(a). The same result approximately applies to the width-extensional mode shown in Fig. 2(b), if $L$ is substituted for $W$. It is difficult to compute an analytical expression for the electromechanical coupling of all the modes without resorting to advanced analysis techniques [15]. The values provided are those associated with the two fundamental modes that offer practical applications for the resonator and that were experimentally detected.

The equivalent mass of the resonator can be computed in the following way:

$$
M_{e q}=\frac{\rho T \iint_{A}\left(u_{x}^{2}+u_{y}^{2}\right) d x d y}{u_{\mathrm{MAX}}^{2}} \approx \rho \frac{W L T}{2}
$$

where $T$ is the thickness of the plate. Equation (6) applies to both the fundamental length and width-extensional mode shapes. It is therefore possible to compute the electromechanical parameters that describe a one-port rectangular plate vibrating in a length-extensional mode [14]

$$
\begin{aligned}
f_{o} & =\frac{1}{2 L} \sqrt{\frac{E_{P}}{\rho}} \quad R_{M} \approx \frac{2 \pi f_{o} M_{e q}}{\eta^{2} Q}=\frac{\pi}{8} \frac{T}{W} \frac{\rho^{\frac{1}{2}}}{E_{P}^{\frac{3}{2}} Q d_{31}^{2}} \\
C_{M} & \approx \frac{\eta^{2}}{\left(2 \pi f_{o}\right)^{2} M_{e q}}=\frac{8}{\pi^{2}} \frac{W L}{T} d_{31}^{2} E_{P} \\
L_{M} & \approx \frac{M_{e q}}{\eta^{2}}=\frac{\rho}{8} \frac{L T}{W} \frac{1}{d_{31}^{2} E_{P}^{2}} \quad C_{O} \approx \varepsilon_{o} \varepsilon_{33} \frac{W L}{T}
\end{aligned}
$$



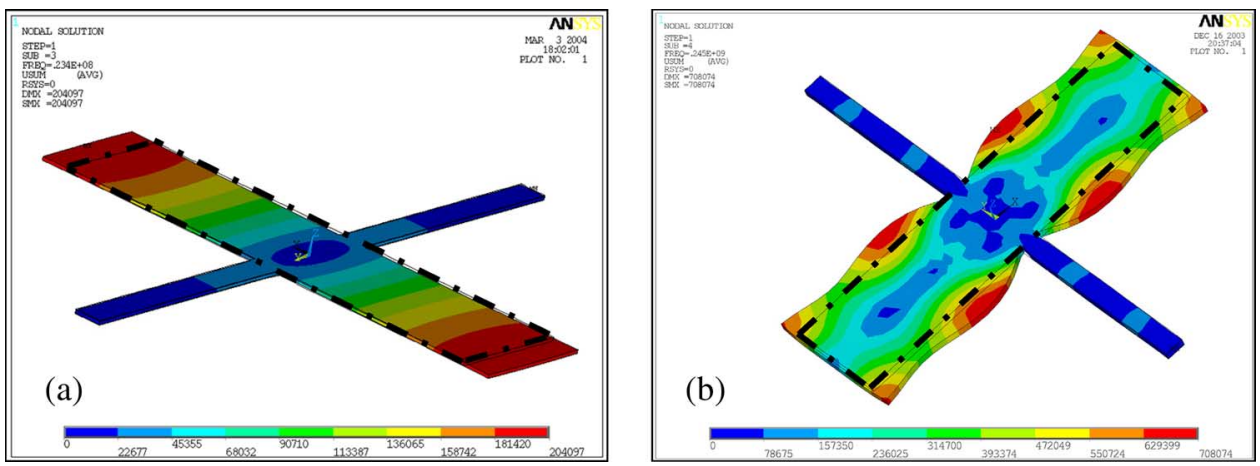

Fig. 2. Fundamental mode shapes detected in AlN contour-mode rectangular plate resonators. The (a) length-extensional mode and (b) width extensional mode are the two most important modes of practical interest. These modes of vibrations are characterized by large strain of the same sign and therefore by low motional resistance.
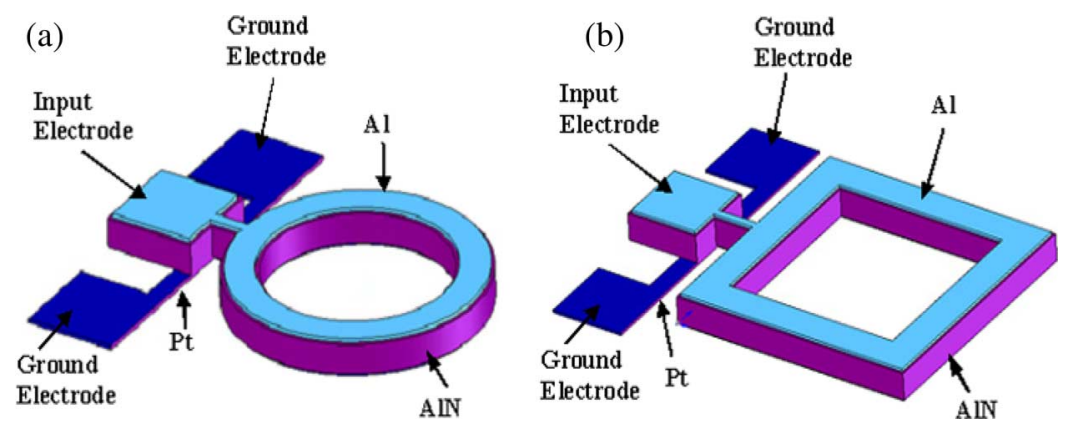

Fig. 3. AlN ring-shaped contour-mode micromechanical resonators: (a) one-port circular ring and (b) one-port square-shaped ring.

where $f_{o}$ is the resonant frequency of the device; $R_{M}, C_{M}$, and $L_{M}$ represent, in accordance with the Butterworth Van Dyke model, the motional components of the resonator, respectively, resistance, capacitance, and inductance; $C_{O}$ is the static parallel capacitance of the device; and $\varepsilon_{33}$ is the relative dielectric constant of AlN in the $\mathrm{z}$ direction. The same values apply for the width-extensional mode of Fig. 2(b) if $L$ is exchanged with $W$ and vice versa.

In conclusion, the equivalent electromechanical parameters of a rectangular plate vibrating either in a length or width extensional contour mode shape were derived. The in-plane dimension of the plate (either length or width) set the resonant frequency. In principle, the designer could act on the second dimension (width for length-extensional mode and length for width-extensional mode) to independently set the motional resistance. As was shown in [5], a certain aspect ratio between length and width of the resonator (generally not larger than one-tenth) needs to be preserved, in order to maintain the desired mode shape and avoid excitation of spurious responses. In fact, large aspect ratios tend to make the structure very compliant and susceptible to flexural vibrations.

\section{DESIGN OF RING-ShaPED RESONATORS}

Fig. 3 shows two implementations of ring-shaped contourmode AlN microresonators. An AlN elastic body shaped in the form of a ring (circular or square shaped, but could be generalized to any number of sides) is sandwiched between $\mathrm{Al}$ and Pt electrodes. An electric field applied across the thickness of the film tends to dilate the structure and makes it vibrate in a breathing mode across its width. As will be shown, the funda- mental dimension that sets the center frequency of the microresonator is the width of the ring. These resonators are one-port devices in which the whole top surface is electroded. This topology guarantees that maximum energy is coupled into the desired mode, minimal motional resistance is obtained, and undesired modes are minimized. A general theory to derive the frequency and mode shape of the ring is presented. The equivalent parameters will be computed only for the approximate case in which the average perimeter of the ring is much larger than its width, which is the case that was experimentally verified.

According to [17], the frequency equation of a circular ring vibrating in a pure radial-extensional mode shape is given by

$$
f(K)=\left|\begin{array}{ll}
b_{11} & b_{12} \\
b_{21} & b_{22}
\end{array}\right|=0
$$

where

$$
\begin{aligned}
b_{11} & =J_{1}(K)\left[M_{1}(K)-(1-\sigma)\right] \\
b_{12} & =Y_{1}(K)\left[N_{1}(K)-(1-\sigma)\right] \\
b_{21} & =J_{1}(L)\left[M_{1}(L)-(1-\sigma)\right] \\
b_{22} & =Y_{1}(L)\left[N_{1}(L)-(1-\sigma)\right] \\
M_{1}(x) & =x J_{0}(x) / J_{1}(x) \quad N_{1}(x)=x Y_{0}(x) / Y_{1}(x) \\
K & =\frac{\omega}{c} R_{\text {out }} \quad L=\frac{\omega}{c} R_{\text {in }} \quad c=\sqrt{\frac{E_{P}}{\rho\left(1-\sigma^{2}\right)}}
\end{aligned}
$$

and $R_{\text {out }}$ is the outer radius of the ring, $R_{\text {in }}$ the inner radius of the ring, $\sigma$ the Poisson's ratio of AlN, $\rho$ its mass density, 


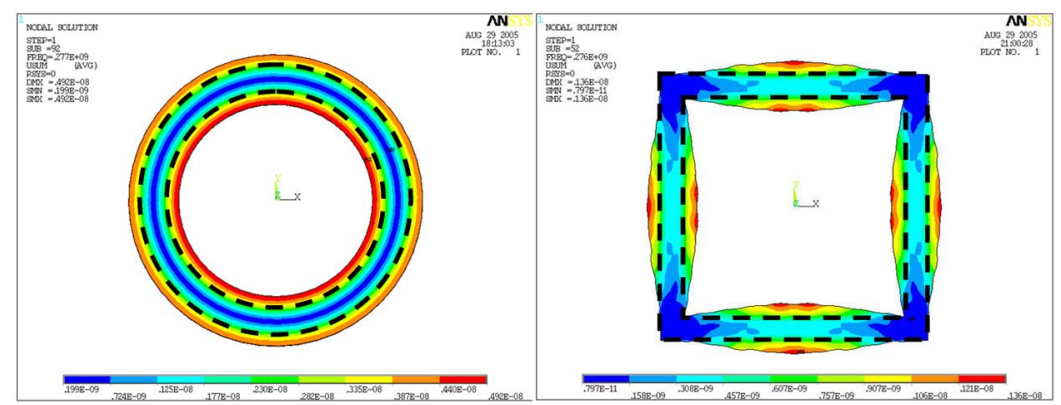

Fig. 4. Mode shapes analysis performed in ANSYS for a $20 \mu \mathrm{m}$ wide and $90 \mu \mathrm{m}$ inner radius circular ring and a $20 \mu \mathrm{m}$ wide and $180 \mu \mathrm{m}$ inner length squareshaped ring. Nondeformed shape is represented by dashed lines. Electrodes were not included in this simulation.

and $E_{p}$ its equivalent Young's modulus, as defined for (1)-(4). Quantities $J$ and $Y$ are Bessel functions of first and second kind, whereas $M$ and $N$ are modified Bessel functions. The mode shape of the ring is described by the following equation [17]:

$$
u_{r}(r)=\left[A \frac{\partial J_{1}(h r)}{\partial r}+B \frac{\partial Y_{1}(h r)}{\partial r}\right]
$$

where $h=\omega / c$ (with $c$ being the film's sound velocity), $r$ is the radial coordinate, and $A$ and $B$ are two constants that can be found by applying the boundary conditions of zero stress at the inner and outer surfaces of the ring. Although accurate, (9) and (10) are fairly complicated and difficult to handle. It can be shown [5] that when the average radius of the ring $R_{\mathrm{AVE}}$ is much larger than the width of the ring itself, the mode of vibration of the ring can be approximated by one of a bar vibrating across its length. It is sufficient to map the length of the bar to the width of the ring and the width of the bar to the average perimeter of the ring to compute the equivalent electromechanical parameters for the ring resonator. This approximation was verified by simulations in ANSYS. The equivalent electrical parameters of a circular ring are therefore expressed as

$$
\begin{aligned}
f_{o} & \approx \frac{1}{2 W} \sqrt{\frac{E_{P}}{\rho\left(1-\sigma^{2}\right)}} \quad R_{M} \approx \frac{\pi}{8} \frac{T}{2 \pi R_{\mathrm{AVE}}} \frac{\rho^{\frac{1}{2}}\left(1-\sigma^{2}\right)^{\frac{1}{2}}}{E_{P}^{\frac{3}{2}} Q d_{31}^{2}} \\
C_{M} & \approx \frac{8}{\pi^{2}} \frac{W 2 \pi R_{\mathrm{AVE}}}{T} \frac{d_{31}^{2} E_{P}}{1-\sigma^{2}} \quad L_{M} \approx \frac{\rho}{8} \frac{W T}{2 \pi R_{\mathrm{AVE}}} \frac{\left(1-\sigma^{2}\right)^{2}}{d_{31}^{2} E_{P}^{2}} \\
C_{O} & \approx \varepsilon_{o} \varepsilon_{33} \frac{2 \pi R_{\mathrm{AVE}} W}{T} .
\end{aligned}
$$

Fig. 4 shows the typical modes of vibration of the circular and square-shaped rings. The same equations apply for the squareshaped ring or a ring with any number of sides as long as we substitute $2 \pi R_{\mathrm{AVE}}$ with the effective average perimeter of the ring. The effective perimeter differs from the real perimeter of the structure by a correction factor $\gamma$, less than one, and takes into account the fact that not all the edges undergo the same displacement as in the case of the circular ring. Let us remind the reader that the values of equivalent electrical parameters are only approximations and should be used mainly as a tool to understand the fundamental parametric trends that affect the performance of the resonator.
It is worth noting that for the ring structure, low values of the motional resistance (less than $200 \Omega$ ) can be set independently of the frequency with more flexibility than in the case of the rectangular plate for which a fixed aspect ratio needed to be preserved. In fact, even if large diameter rings are employed, the circular ring structure maintains an overall larger stiffness than plates with equivalent motional resistance.

In order to maximize the $\mathrm{Q}$ of the resonator, quarter-wave tethers were employed. These tethers are located on one or either side of the resonator. Their effect on $\mathrm{Q}$ is better described in the following sections. It can be intuitively anticipated that the use of a single anchor improves the quality factor of the device and the use of notched solutions (see Fig. 9) reduces the appearance of spurious mode shapes.

\section{FREQUENCY SETTING}

As evident from the previous sections, the key aspect of AlN contour-mode resonators is to have their center frequency set by the in-plane dimensions and therefore be lithographically definable. Other factors such as electrode thickness, anchor size, and sidewall angle also affect to a second order the resonant frequency of these devices.

The metal electrodes have a finite mass and specific sound velocity. As for any mechanical system, appending an external mass affects its resonant frequency. The mass density of $\mathrm{Pt}$ is about 6.5 times larger than that of AlN, whereas its modulus of elasticity is 2.4 times smaller. Al has a mass density that is 1.2 times smaller than that of AlN and a modulus of elasticity that is 5.8 times smaller. To a first degree of approximation, the effect of mass loading on the center frequency of the microstructure is dominated by the Pt electrode, and $\mathrm{Al}$ (generally thinner than $\mathrm{Pt}$ because of its higher conductivity) can be neglected. The effect of mass loading on the center frequency due to Pt can be computed in the following way [18]:

$$
f_{N E W}=f_{o} \sqrt{\frac{\left(1+\frac{E_{P t} A_{P t}}{E_{P} A_{P}}\right)}{\left(1+\frac{\rho_{P t} A_{P t}}{\rho_{P} A_{P}}\right)}}
$$

where $f_{O}$ is the unloaded center frequency, $E$ is the equivalent Young's modulus, and $A$ is the cross-sectional area perpendicular to the main direction of propagation of the elastic wave in the piezoelectric body. The subscripts $\mathrm{Pt}$ and $\mathrm{P}$ refer to platinum and the piezoelectric resonator, respectively. Fig. 5 shows the 


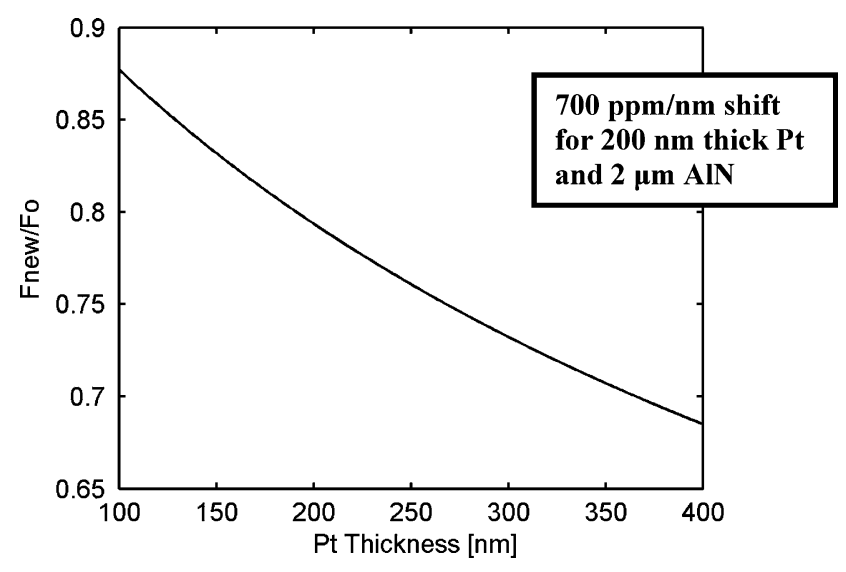

Fig. 5. Shift $\mathrm{f}_{\text {new }} / \mathrm{f}_{\mathrm{o}}$ versus Pt thickness for a 2 - $\mu$ m-thick AlN film. For a 200-nm-thick Pt electrode, the frequency shift is approximately $700 \mathrm{ppm} / \mathrm{nm}$. Results are based on (12).

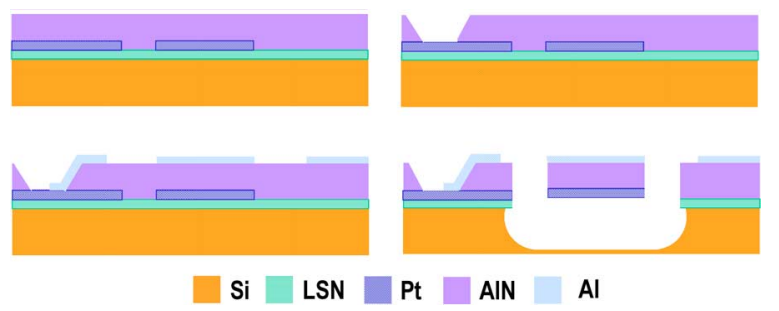

Fig. 6. Schematic view of the process flow used to fabricate AlN piezoelectric resonators. (a) Low stress nitride deposition by LPCVD, followed by Pt patterning by liftoff and AIN sputter deposition; (b) open via access to bottom Pt electrode through $\mathrm{AlN}$; (c) deposition of top $\mathrm{Al}$ electrode and patterning by dry etch in $\mathrm{Cl}_{2}$-based chemistry. AlN is wet etched by hot $\mathrm{H}_{3} \mathrm{PO}_{4}\left(160{ }^{\circ} \mathrm{C}\right)$; (d) $\mathrm{Cl}_{2}$-based dry etching of AlN resonant devices and dry release in $\mathrm{XeF}_{2}$.

fractional change in frequency $f_{\text {new }} / f_{o}$ that occurs when the $\mathrm{Pt}$ thickness is changed between 100 and $400 \mathrm{~nm}$. It is clear that the impact of Pt thickness on the resonator center frequency is significant ( $\mathrm{Al}$ has an impact about one-tenth of $\mathrm{Pt}$ ). The analytical results were also verified with ANSYS and showed close agreement within 3\%. Despite this loading effect, the manufacturing tolerances on thickness variation are less stringent than that reported for FBAR (thickness mode resonators), for which less than $0.1 \%$ uniformity across the wafer is demanded. Contour-mode resonators require tolerances on the thickness uniformity that are about $10 \times$ larger $(\sim 1 \%)$, therefore simplifying the fabrication process. Tolerances for the lateral dimensions of the contour-mode devices are similar to those for the film thickness of FBAR technology, but state-of-the-art integrated circuit manufacturing tools excel at defining small features lithographically, therefore reducing the challenge of accurate frequency setting. Ultimately, the realization of high frequency and accurate contour-mode structures could result in a more economically viable solution than existing FBAR resonators.

A slight drawback of the release process (see Fig. 6 and next section on fabrication) is that some undercut is experienced underneath the anchor location. Unfortunately, this phenomenon renders more complicated computing the equivalent stiffness of the anchors and their effect on the center frequency of the resonator. In any case, the influence of the anchor stiffness on the

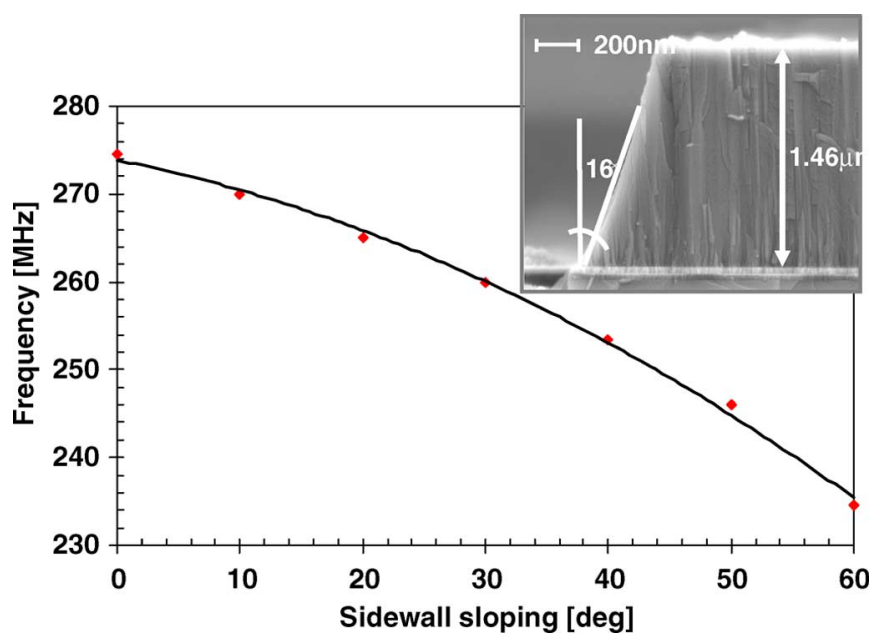

Fig. 7. Effect of sidewall sloping (as shown in inset) on the fundamental frequency of an unelectroded, $20-\mu \mathrm{m}$-wide circular ring resonator as the one shown in Fig. 9(a).

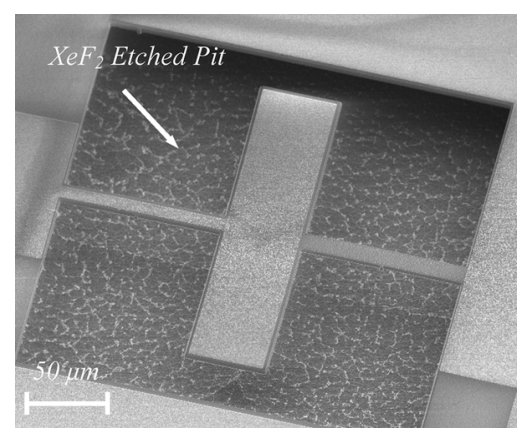

Fig. 8. SEM of a one-port $200 \times 50 \mu \mathrm{m}$ AlN rectangular plate.

resonator frequency is a second-order effect and can be considered negligible to a first degree of approximation.

The slope of the AlN sidewall has instead a more significant effect on the center frequency. As shown in Fig. 7, ANSYS simulations for an unelectroded, 20- $\mu \mathrm{m}$-wide AlN circular ring predicts a downshift in the resonant frequency with an increase in the sidewall angle. This phenomenon can be explained by a change in the average width of the ring due to an effective trapezoidal cross section with a bottom side wider than the one drawn in the CAD layout. According to these considerations, it can be extrapolated that the effect of the sidewall sloping is going to have a more significant impact on higher frequency devices, for which the difference between the top and bottom sides approaches the fundamental wavelength of the resonator. Accurate control of sidewall sloping will be necessary for reliable and high-yield fabrication of contour-mode resonators.

\section{RESONATOR FABRICATION}

A robust four-mask, potentially post-CMOS compatible process has been used to fabricate these devices (Fig. 6). An approximately $2-\mu \mathrm{m}$-thick AIN film is sandwiched between a bottom platinum electrode and a top aluminum electrode. AlN films were sputter-deposited using a single-module AMS physical vapor deposition (PVD) sputtering tool. C-axis oriented, highly crystalline films with rocking curve values below $2^{\circ}$ were obtained. The fabrication process starts by patterning 

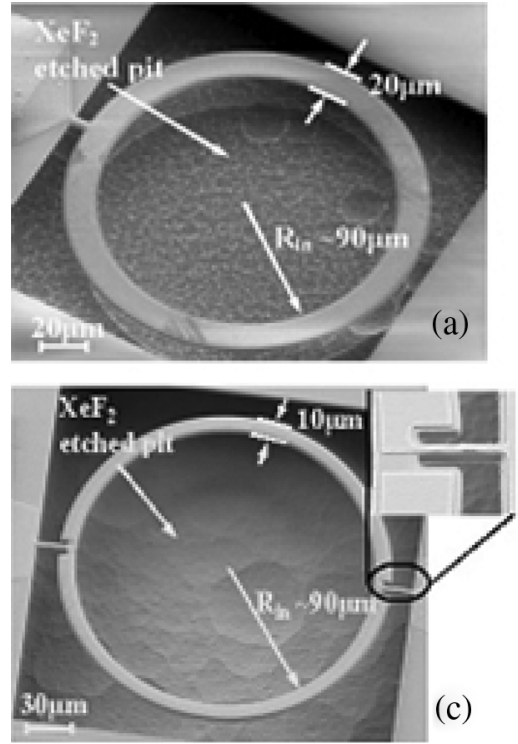
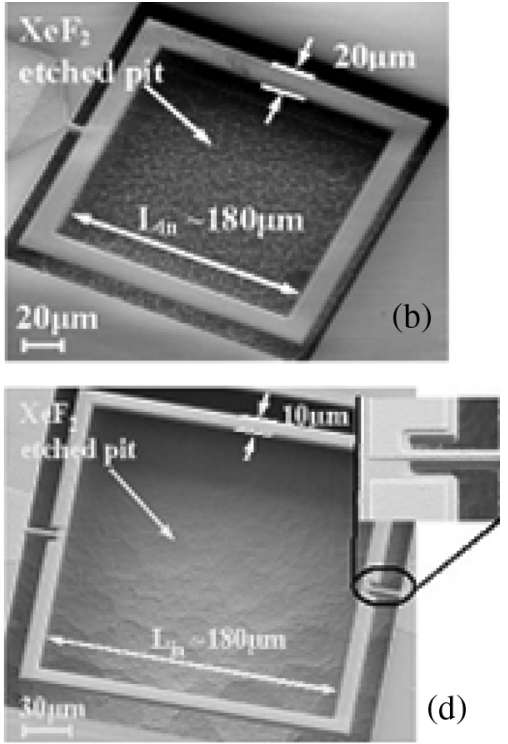

Fig. 9. SEM image of (a) a single-support circular-shaped contour-mode 20- $\mu$ m-wide ring resonator; (b) a single-support square-shaped contour-mode 20- $\mu$ m

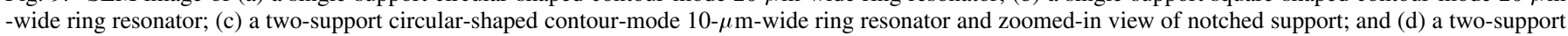
square-shaped contour-mode $10-\mu \mathrm{m}$-wide ring resonator and zoomed-in view of notched support.

the bottom Pt electrode on a low-stress nitride buffer layer in order to reduce parasitic capacitance and electrical losses. In addition, patterning of the Pt electrode offers the opportunity to lithographically fine-tune the center frequency of the resonator by mass loading. Openings to contact the bottom electrode are quickly wet etched through AlN in a hot (160 $\left.{ }^{\circ} \mathrm{C}\right)$ phosphoric bath. The top $\mathrm{Al}$ electrode is patterned by dry etching. $\mathrm{Cl}_{2}$-based dry etching has been used to pattern AlN and obtain fairly straight sidewalls $\left(16^{\circ}\right.$ from vertical). During the dry etch process, the AlN film is masked by oxide deposited either by electron cyclotron resonance or by low-temperature chemical vapor deposition techniques $\left(\mathrm{T}_{\max }<400^{\circ} \mathrm{C}\right)$. When low temperature oxide is used, the top $\mathrm{Al}$ electrode is protected by a thin $(<30 \mathrm{~nm})$ layer of $\mathrm{Nb}$ that is subsequently removed with the remaining oxide during a $\mathrm{CF}_{4}$-based dry etch step. The structures are released by dry etching of silicon in $\mathrm{XeF}_{2}$, thereby eliminating stiction between the devices and substrate and significantly increasing yield.

Fig. 8 shows a $200 \times 50 \mu \mathrm{m}$ rectangular plate AlN resonator that was realized using the aforementioned process. The same process was employed to fabricate the circular and square shaped rings that are represented in Fig. 9. Fig. 9(c) and (d) shows notched solutions that were implemented to minimize anchor interference with the resonator mode shape.

\section{EXPERIMENTAL RESULTS}

The fabricated micromechanical resonators were tested in a Janis micromanipulated RF probe station at atmospheric pressure and under 5 mTorr vacuum. Ground-signal-ground probes from Picoprobe were used. $S_{11}$ parameters were extracted for one-port devices. No interface circuitry between the resonator and the network analyzer was needed. Given the low impedance values shown by the resonators, it was possible to directly measure the frequency response of the resonators. $S_{11}$ parameters were converted into equivalent admittances using an Agilent
E8358A network analyzer. One-port $\mathrm{S}_{11}$ parameter calibration (SOL) was performed using short $(\mathrm{S})$ open $(\mathrm{O})$, and load $(\mathrm{L})$ on a ceramic substrate. The quality factor $\mathrm{Q}$ of the resonators was extracted directly from the admittance plot by measuring the $3 \mathrm{~dB}$ bandwidth of the device under test.

\section{A. Rectangular Plates}

Different aspect ratios (length/width ratio) and sizes were considered for the rectangular plates. It was experimentally shown that aspect ratios of 4:1 offer slightly higher quality factors and correspondingly lower motional resistance than plates having 2:1 aspect ratios. Also, low values of motional resistance below $1 \mathrm{k} \Omega$ were obtained for plates with lengths above $200 \mu \mathrm{m}$. For the aforementioned reasons, experimental results related to $200 \times 50 \mu \mathrm{m}$ plates are presented and for which a large number of data were collected. Given the high electromechanical coupling provided by the entire top surface being electroded, the plate was excited into two fundamental mode shapes: the length-extensional mode [Fig. 2(a)] and the width-extensional mode [Fig. 2(b)]. Other weakly excited modes are not detected electrically due to the static capacitive response of the device caused by $C_{o}$.

Fig. 10 shows the admittance curves for a typical rectangular plate excited in both fundamental contour modes. These curves were extracted from $\mathrm{S}_{11}$ parameters and measured at atmospheric pressure. Q ranging from 2000 to 3000 were obtained at atmospheric pressure. It is very important to notice that the width-extensional mode can achieve a motional resistance as low as $125 \Omega$ at $85.4 \mathrm{MHz}$. Although higher Qs were achieved with the length-extensional mode, the width-extensional mode has a lower motional resistance given its larger electromechanical coupling proportional to the overall length and not only the width of the structure. Because of its lower impedance, the width-extensional mode is more amenable to the implementation of intermediate-frequency filters [19], whereas the 
TABLE I

COMPARISON BETWEEN THEORETICAL AND EXPERIMENTAL RESULTS FOR THE EQUIVALENT ELECTRICAL COMPONENTS (BASED ON BVD) OF RECTANGULAR Plate Resonator of Fig. 10 and CirCular Ring OF Fig. 11(a). The Following VAlues Were Used: $\mathrm{E}_{\mathrm{P}}=385 \mathrm{GPa}, \rho=5,080 \mathrm{~kg} / \mathrm{m}^{3}, \mathrm{~d}_{31}=2 \mathrm{pC} / \mathrm{N}$,

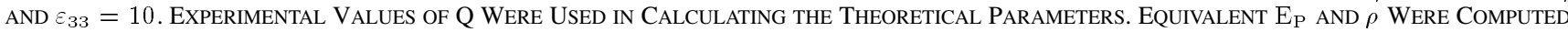

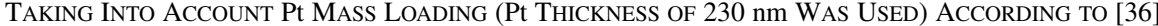

\begin{tabular}{|l|c|c|c|c|c|c|}
\hline \multirow{2}{*}{$\begin{array}{l}\text { Resonator } \\
\text { Variable }\end{array}$} & \multicolumn{2}{|c|}{ Length-Ext. Plate } & \multicolumn{2}{c|}{ Width-Ext. Plate } & \multicolumn{2}{c|}{ Circular Ring } \\
\cline { 2 - 7 } & THEORY & EXPERIM. & THEORY & EXPERIM. & THEORY & EXPERIM. \\
\hline $\mathbf{f}_{\mathbf{0}}[\mathbf{M H z}]$ & 21.76 & 19.96 & 87.06 & 85.40 & 227.41 & 223.90 \\
\hline $\mathbf{C}_{\mathbf{0}}[\mathbf{p F}]$ & 0.44 & 0.81 & 0.44 & 0.81 & 0.56 & 1.25 \\
\hline $\mathbf{L}_{\mathbf{M}}[\boldsymbol{\mu H}]$ & 8.57 & 15.07 & 535.5 & 629 & 57.2 & 92.12 \\
\hline $\mathbf{C}_{\mathbf{M}}[\mathbf{f F}]$ & 6.24 & 4.22 & 6.24 & 5.52 & 8.56 & 5.48 \\
\hline $\mathbf{R}_{\mathbf{M}}[\mathbf{\Omega}]$ & 434 & 700 & 139 & 125 & 32 & 54 \\
\hline
\end{tabular}
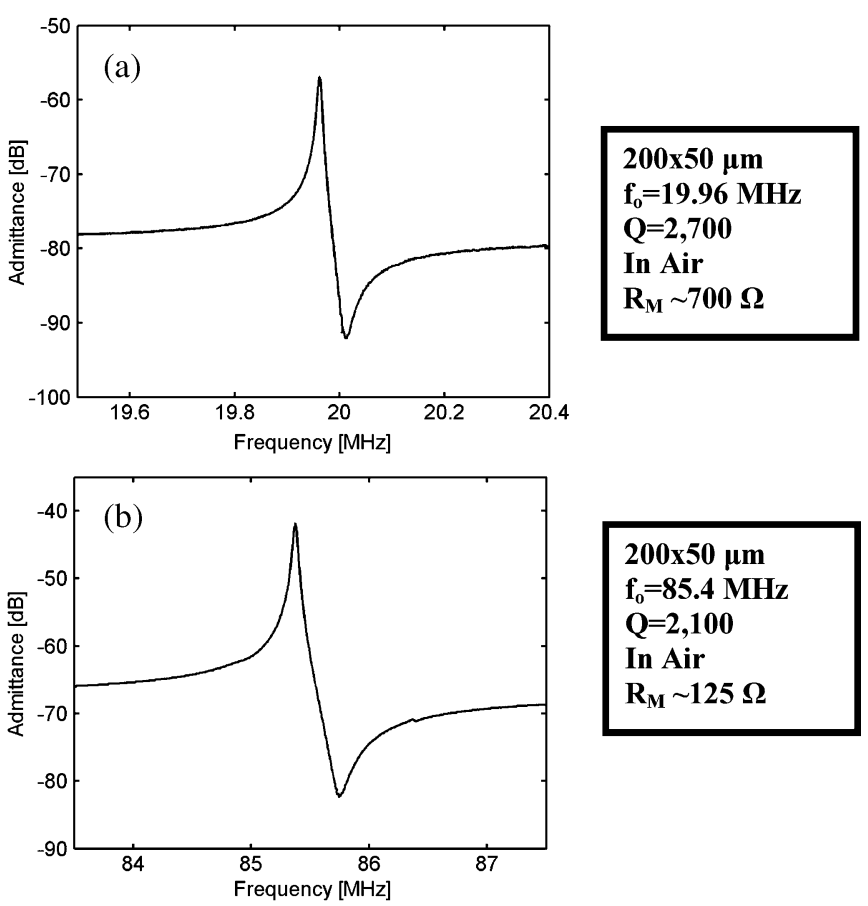

200x50 $\mu \mathrm{m}$
$\mathbf{f}_{\mathbf{0}}=85.4 \mathrm{MHz}$
$\mathrm{Q}=2,100$
In Air
$R_{M} \sim 125 \Omega$

Fig. 10. (a) Typical admittance plot for a one-port rectangular plate resonator excited in a length-extensional contour mode and (b) typical admittance plot for a one-port rectangular plate resonator excited in a width-extensional contour mode.

lower frequency mode could be used to realize frequency reference elements. Table I compares the frequency and equivalent electrical parameters extracted from the experimental curves of these rectangular plate resonators with the values obtained from the theoretical derivation. The $\mathrm{Q}$ values used in the theoretical calculations are the same as were extracted from the experimental response of the resonator, since an adequate way to determine, a priori, the overall $\mathrm{Q}$ of the device has not yet been identified. The frequency values are predicted with a high degree of accuracy once the electrode mass loading effect is taken into account. Although the experimental and theoretical values for the electrical parameters are not closely matched, the agreement is sufficient to justify the use of (7) for the initial design of these resonators. The difference in the static capacitance is introduced by parasitic capacitances in the substrate which were not taken into account in (7). These parasitic capacitances limit the resonator performance at higher frequencies. Resonator size and therefore static capacitance scale in fact with frequency. At high frequencies, the response

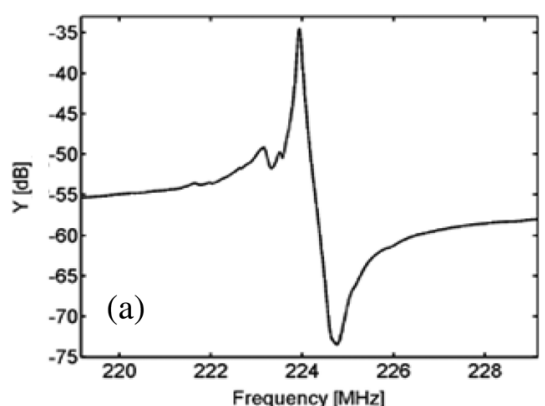

$$
\begin{aligned}
& \mathrm{W}=20 \mu \mathrm{m} \\
& R_{\text {in }}=90 \mu \mathrm{m} \\
& \text { un-notched } \\
& \mathbf{f}_{\mathbf{o}}=\mathbf{2 2 3 . 9} \mathrm{MHz} \\
& Q^{=2,400} \\
& R_{\mathbf{M}} \sim \mathbf{5 6} \Omega
\end{aligned}
$$
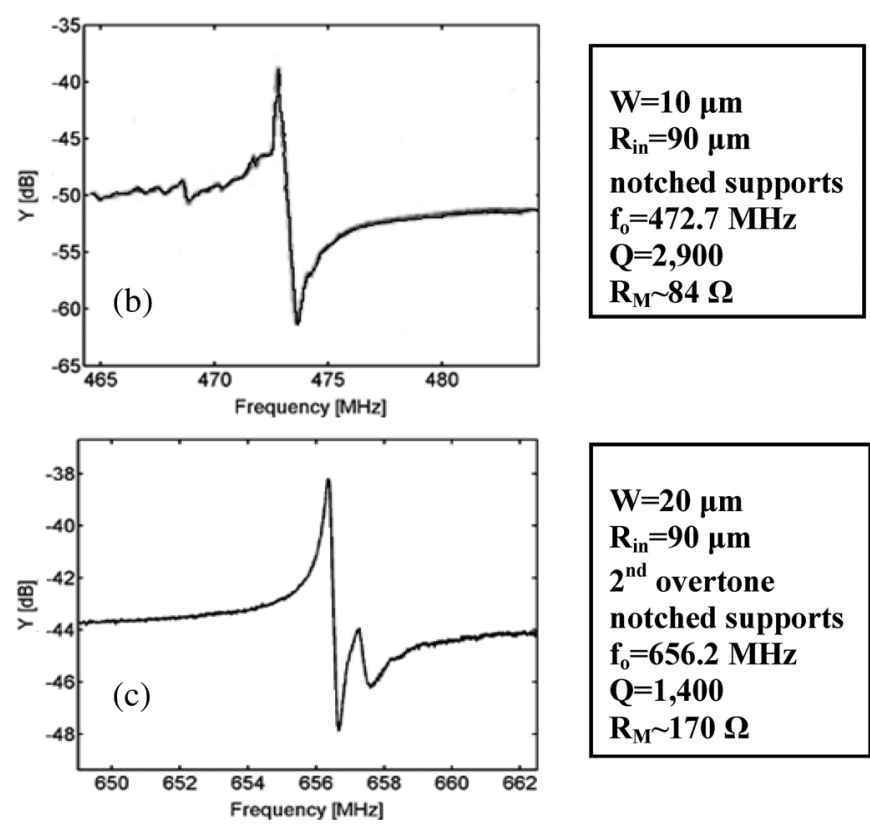

Fig. 11. (a) Admittance plot for a single-support $223.9 \mathrm{MHz}$ circular ring resonator with a width of $20 \mu \mathrm{m}$ and inner radius of $90 \mu \mathrm{m}$. (b) Admittance plot for a notched-support $472.7 \mathrm{MHz}$ circular ring resonator with a width of $10 \mu \mathrm{m}$ and inner radius of $90 \mu \mathrm{m}$. (c) Admittance plot for the second overtone of a notched-support circular ring resonator with a width of $20 \mu \mathrm{m}$ and inner radius of $90 \mu \mathrm{m}$.

of small capacitance devices will be masked by parasitic capacitances that instead stay constant with frequency.

\section{B. Circular and Square-Shaped Rings}

Contour-mode micromechanical ring-shaped resonators were fabricated using the same process. To better understand the effect of anchors, as shown in Fig. 9(c) and (d), notches were introduced in some of the structures in order to minimize the interference of the anchor on the mode shape. Fig. 11(a) represents the typical response of a circular ring microresonator with a single 


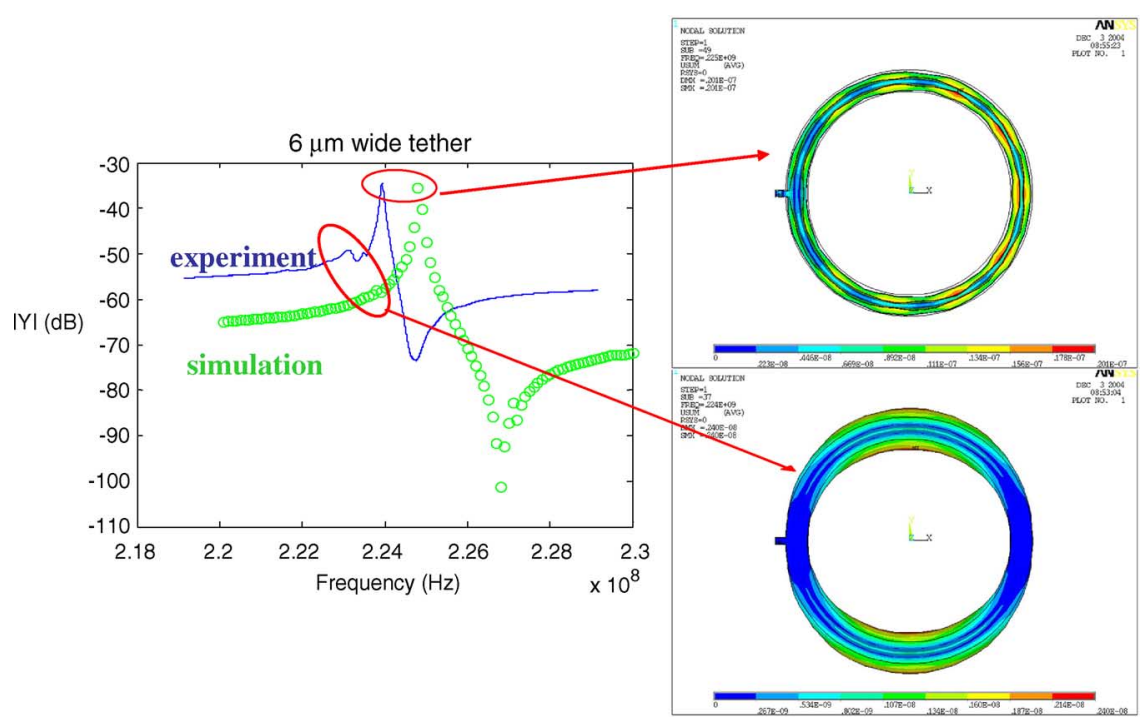

Fig. 12. Ansys simulation of the $20 \mu \mathrm{m}$ ring resonator response of Fig. 10(a) showing the origin of the spurious response in proximity of the main resonant peak. This spurious mode does not appear if the anchor is removed.

unnotched support. Motional resistance as low as $56 \Omega$ and $\mathrm{Q}$ of $2400 \mathrm{in}$ air were recorded for this $223.9 \mathrm{MHz}$ resonator. A comparison of identical resonators showed that notched supports did not substantially improve the $\mathrm{Q}$ of the resonator but reduced the interference between the anchors and the resonator motion, especially for resonators with smaller ring widths or with two anchors. Less mechanical interference translates into a cleaner electrical signal with fewer spurious resonances. As shown in Fig. 12, the spurious mode in close proximity of the main resonant peak and present in the responses of Figs. 11(a) and 18 is caused by the use of the tether. This effect was even more significant when two anchors were introduced and the two peaks reached the same magnitude. This phenomenon was definitely attenuated when notched supports were introduced as shown by the cleaner response of the $472.2 \mathrm{MHz}$ Fig. 11(b).

Table I compares experimental and theoretical values of the equivalent electromechanical parameters of the $223.9 \mathrm{MHz}$ resonator. Except for a necessary assumption on the $\mathrm{Q}$ value, here obtained from experimental values, we conclude that (11) is a valuable tool for the design of piezoelectric ring resonators despite the slight difference between the theoretical and experimental values.

Fig. 11(b) presents the highest Q of 2900 obtained for a circular ring resonator at $472.7 \mathrm{MHz}$ with notched supports, a width of $10 \mu \mathrm{m}$, and an inner radius of $90 \mu \mathrm{m}$. The motional resistance of this resonator is approximately $84 \Omega$. To further prove the less intrusive nature of notched supports, a $20-\mu \mathrm{m}$ -wide ring with $90 \mu \mathrm{m}$ inner radius could be excited in its second overtone reaching a frequency of $656.2 \mathrm{MHz}$ with $\mathrm{Q}$ of 1400 and $\mathrm{R}_{\mathrm{M}} \sim 170 \Omega$ Fig. 11(c). It was also possible to control the value of the motional resistance of these resonators by changing the size of the inner radius. A $20-\mu \mathrm{m}$-wide circular ring with an inner radius of $40 \mu \mathrm{m}$ exhibits a motional resistance of $204 \Omega$ at 227.4 MHz. This reduction in size affects the quality factor of these resonators that is now reduced to 1100 . This is probably due to the change in the aspect ratio between anchor size

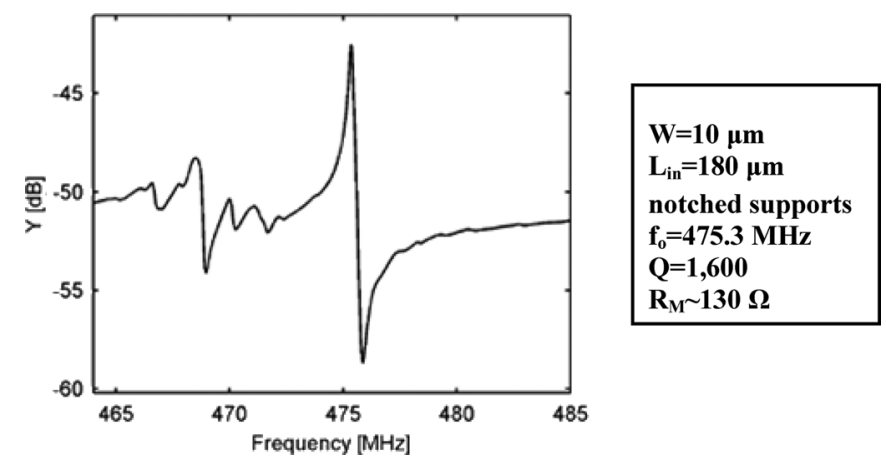

Fig. 13. Admittance plot for a 475.3 MHz notched-support square-shaped ring resonator with a width of $10 \mu \mathrm{m}$ and inner length of $180 \mu \mathrm{m}$.

(kept constant) and resonator size, therefore causing larger energy leak through the anchor in the smaller resonator.

Square-shaped micromechanical ring resonators were also excited in width-extensional mode shapes. The typical response for a 10- $\mu \mathrm{m}$-wide resonator with inner ring length of $180 \mu \mathrm{m}$ is shown in Fig. 13. Although these devices were able to reach a frequency as high as $475.3 \mathrm{MHz}$ with respectable Q of 1600 and $\mathrm{R}_{\mathrm{M}}$ approximately $130 \Omega$, these resonators show several spurious modes which cannot be suppressed even when notched supports are used. The authors presume that the presence of $90^{\circ}$ corners causes distortion in the width extensional mode shape of the square-shaped ring and induces spurious vibrations in proximity of the fundamental mode.

\section{TEMPERATURE COEFFICIENT OF FREQUENCY}

As has been shown in the design sections, the resonant frequency of a micromechanical resonator depends on its geometry (in plane dimensions for contour modes), equivalent modulus of elasticity, and mass density. Because all these parameters vary with temperature, the center frequency is subject to fluctuations whenever the temperature changes. According to the spec- 
TABLE II

EXPERIMENTAL DATA FOR THE TEMPERATURE COEFFICIENT OF FREQUENCY (TCF) OF THE CONTOUR-MOdE AIN RESONATORS PRESENTED IN THIS PAPER

\begin{tabular}{|l|c|c|}
\hline Resonant Structure & Mode Shape & TCF $\left[\mathrm{ppm} /{ }^{\circ} \mathbf{C}\right]$ \\
\hline \multirow{2}{*}{ Rectangular Plate } & Length-Ext. & -26 \\
\cline { 2 - 3 } & Width-Ext. & -25 \\
\hline Circular Ring & Radial-Ext. & -25 \\
\hline Square-Shaped Ring & Width-Ext. & -25 \\
\hline
\end{tabular}

ification for quartz crystals used in time-keeping applications for handsets, variations of a few $(<50)$ parts per million (ppm) over the whole temperature range of operation (generally -25 to $+85^{\circ} \mathrm{C}$ ) are demanded. This is the primary reason why specific and expensive crystal cuts or on-chip digital compensation (DCXO) are needed for oscillators used in wireless communications. For filtering applications, the specifications are somewhat more relaxed and generally no compensation is needed. Filters are generally designed with slightly wider bandwidths to accommodate for temperature-induced frequency shifts.

The temperature coefficient of frequency(TCF) of a resonator is generally expressed in $\mathrm{ppm} /{ }^{\circ} \mathrm{C}$ and is given by

$$
\mathrm{TCF}=\frac{1}{f} \frac{\partial f}{\partial T}=-\frac{1}{a} \frac{\partial a}{\partial T}+\frac{1}{2} \frac{1}{E_{P}} \frac{\partial E_{P}}{\partial T}-\frac{1}{2} \frac{1}{\rho} \frac{\partial \rho}{\partial T}
$$

where $a$ is the fundamental geometrical parameter that sets the center frequency and $T$ denotes temperature. This equation is very general and does not take into account the particular strain distribution in the structure or any residual stress. Although approximate, it offers a good estimate for the TCF of AlN. It is worth noting that for contour-mode resonators, differently from tuning fork resonators [20], the mismatch between the temperature coefficient of the piezoelectric stack and the silicon substrate is negligible to a first degree of approximation. This is because either the AlN structures have a single anchor or the modes of vibration have an equivalent stiffness at the anchoring location that is much larger than the stiffness of the anchor itself; therefore any deformation at the clamping location is negligible.

In general, we can state that for contour-mode resonators

$$
\mathrm{TCF}=-\alpha_{1}+\frac{1}{2} \frac{\partial \ln E_{P}}{\partial T}+\frac{1}{2}\left(2 \alpha_{1}+\alpha_{3}\right)
$$

where $a_{1}$ and $a_{3}$ are the linear coefficients of thermal expansion for AlN in the 1 (in the plane of the film) and 3 (out of plane) directions, respectively; $\partial \ln E_{P} / \partial T$ is a coefficient that can be found in the literature [21] and describes the temperature variation of the in-plane modulus of elasticity. For AlN, the largest contribution to the TCF comes from the equivalent in-plane modulus of elasticity $\left(\sim-37 \mathrm{ppm} /{ }^{\circ} \mathrm{C}\right)$, whereas $a_{1}$ and $a_{3}$ take on values of 4.2 and $5.3 \mathrm{ppm} /{ }^{\circ} \mathrm{C}$, respectively. According to this theoretical derivation, the TCF of AlN should be around $-16 \mathrm{ppm} /{ }^{\circ} \mathrm{C}$. Experimental values for the different types of resonators and modes of vibrations are reported in Table II with typical values of around $-25 \mathrm{ppm} /{ }^{\circ} \mathrm{C}$ being recorded. The microstructures were placed on a temperature-controlled chip holder and heated between room temperature and 100 ${ }^{\circ} \mathrm{C}$ (cooling below room temperature was not performed). The
TCF shows, to a first degree of approximation, a linear behavior over the range of temperatures tested. All the resonators show TCFs slightly larger than the theoretically predicted value. It is believed that the metals used for the electrodes and some residual stress that were not taken into account in the theoretical model might affect the experimental value. Although the TCF of AlN is acceptable for filtering applications, it is relatively large for timekeeping functions and needs to be compensated. Its linear behavior simplifies on-chip electronic techniques that can be used for compensation, but mechanical or material related techniques [22], [23] should also be employed to reduce the TCF to less than $-1 \mathrm{ppm} /{ }^{\circ} \mathrm{C}$. A proposed method to tune the center frequency of the resonator and compensate for slight temperature variations involves the use of a dc bias superimposed on the ac driving signal. By purely piezoelectric means of actuation acting on the $d_{33}$ coefficient, the structure undergoes dimensional changes when a dc bias is applied. In theory, the frequency shift for contour-mode resonator due to an applied dc voltage $V$ is given by

$$
\frac{1}{f} \frac{\partial f}{\partial V}=-\frac{1}{a} \frac{\partial a}{\partial V}-\frac{1}{2} \frac{1}{\rho} \frac{\partial \rho}{\partial V}=\frac{d_{33}}{2 T}
$$

where $T$ is the film thickness.

Unfortunately, the effect of such dc bias is not significant as theoretically predicted $(1.7 \mathrm{ppm} / \mathrm{V})$ and experimentally $(4.4$ $\mathrm{ppm} / \mathrm{V}$ ) verified for a 1.5- $\mu \mathrm{m}$-thick film and can be used only for fine-tuning of the center frequency. Although the inverse proportionality between frequency tuning and film thickness was experimentally demonstrated (frequency tuning changes from 4.4 to $3.5 \mathrm{ppm} / \mathrm{V}$ when film thickness is changed from 1.5 to $2 \mu \mathrm{m}$ ), there is a discrepancy between the theoretical value and the experimental results. The cause of such discrepancy has not yet been identified.

\section{QUALITY FACTOR}

The quality factor $\mathrm{Q}$ of a resonator is a direct measure of the energy lost per cycle. The higher the $\mathrm{Q}$, the lower the energy lost

$$
Q=\frac{2 \pi \cdot \text { EnergyStoredperCycle }}{\text { EnergyDissipatedperCycle }}
$$

A high quality factor is therefore desirable because it minimizes the amount of energy that is dissipated. A high quality factor also positively affects the performance of timekeeping oscillators by reducing phase noise. For filtering application, a high Q in combination with a low $R_{M}$ translates into lower insertion losses, therefore improving the overall signal transmission and reducing the specifications on gain elements such as low-noise amplifiers.

This section discusses the main factors that affect the $\mathrm{Q}$ of AlN contour-mode micromechanical resonators and present some initial experimental results that offer insight towards Q improvement.

Energy loss mechanisms in micromechanical resonators have been widely studied in the literature [24]-[28]. The following are among the most significant sources of energy loss that have been identified: 

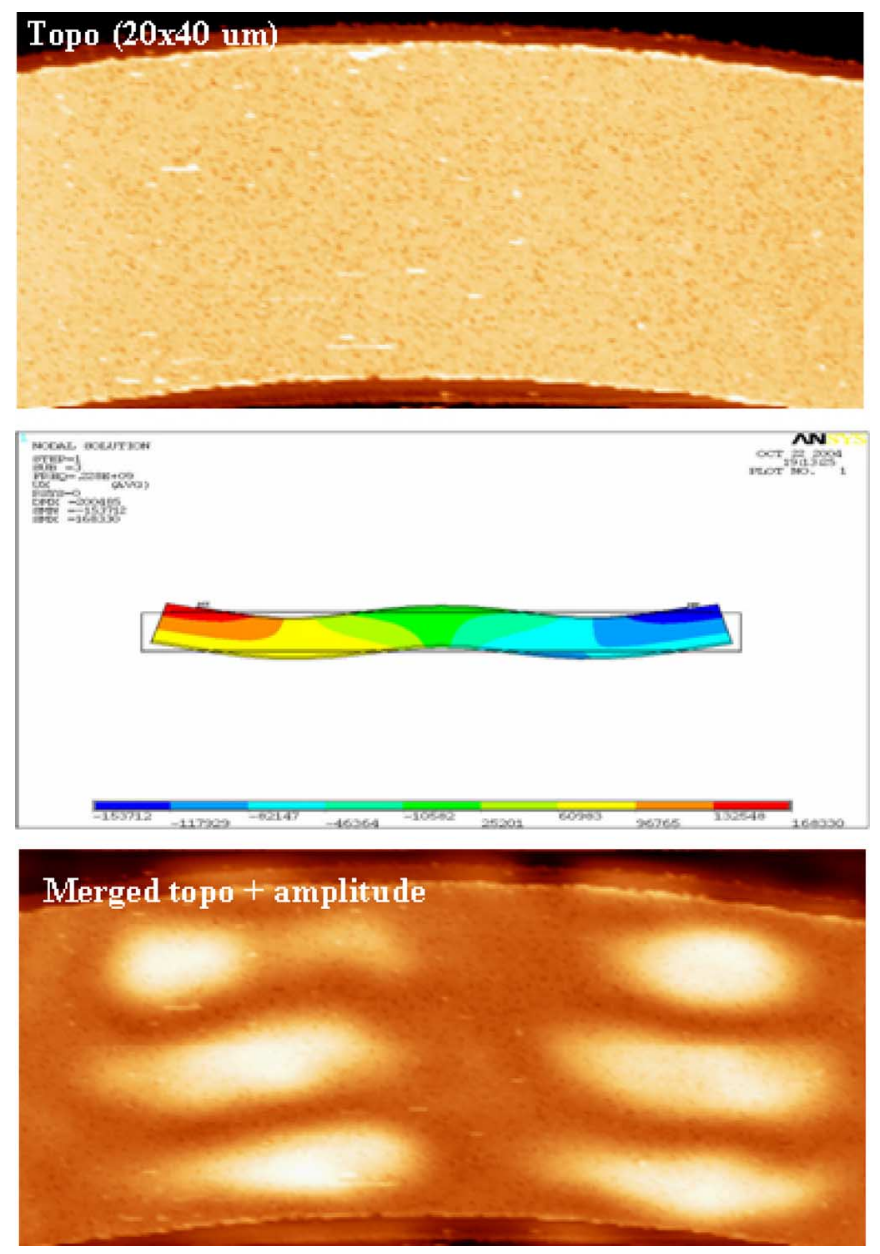

Fig. 14. AFM characterization of out-plane motion in circular ring structures and cross-sectional view of ANSYS simulations showing the superposition of purely radial-extensional vibrations with out-of-plane deflections. It is believed that the asymmetry in the materials stack (different metals) and the sloped sidewalls cause out-of-plane deflections.

- thermoelastic dissipation $Q_{\mathrm{TED}}$;

- anchor losses $Q_{\mathrm{ANC}}$;

- air damping $Q_{\mathrm{AIR}}$;

- electrical loading due to electrode resistivity $Q_{\mathrm{ELC}}$;

- intrinsic material losses $Q_{\mathrm{MAT}}$ either in the AlN film or in the metal electrodes.

In addition, the presence of spurious modes superimposed or in close proximity of the resonator center frequency should be accounted as important mechanisms of energy dissipation [29]. This loss mechanism can be represented by a general, $Q_{\mathrm{MEC}}$, which includes any other process of mechanical energy leakage related to the specific mode shape. $Q_{\mathrm{MEC}}$ will not be specifically addressed in this discussion. It is important to note that all these loss mechanisms affect the overall Q of the structure in this way

$$
\frac{1}{Q}=\frac{1}{Q_{\mathrm{TED}}}+\frac{1}{Q_{\mathrm{ANC}}}+\frac{1}{Q_{\mathrm{AIR}}}+\frac{1}{Q_{\mathrm{ELC}}}+\frac{1}{Q_{\mathrm{MAT}}}+\frac{1}{Q_{\mathrm{MEC}}} .
$$

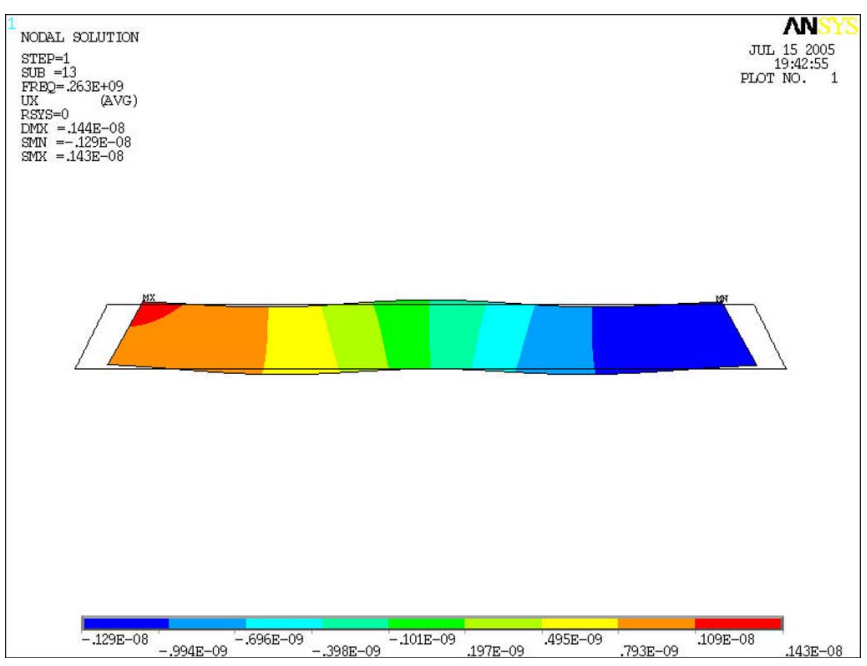

Fig. 15. Cross-sectional view of ANSYS simulation showing the out-of-plane motion of a ring resonator due to linearly sloping sidewalls.

TABLE III

STATISTICAL DATA FOR ANCHOR LOSS STUDY FOR A $20-\mu \mathrm{m}$-WIDE RING WITH $90 \mu \mathrm{m}$ INNER RADIUS. THREE DATA SAMPLES WERE TAKEN FOR EACH Support Size. "Ave." Stands For Average Value. "Span” Is Max Minus MIN

\begin{tabular}{|c|c|c|c|c|}
\hline $\begin{array}{c}\text { Support } \\
\text { Width }[\boldsymbol{\mu m}]\end{array}$ & $\begin{array}{c}\text { Ave. } \mathbf{f}_{\mathbf{o}} \\
{[\mathbf{M H z}]}\end{array}$ & $\begin{array}{c}\text { Span } \mathbf{f}_{\mathbf{0}} \\
{[\mathbf{M H z}]}\end{array}$ & $\begin{array}{c}\text { Ave. } \\
\mathbf{Q}\end{array}$ & $\begin{array}{c}\text { Span } \\
\mathbf{Q}\end{array}$ \\
\hline 6 & 224.8 & 2.6 & 2400 & 700 \\
\hline 10 & 225.2 & 2.8 & 2330 & 300 \\
\hline 20 & 225.0 & 2.9 & 2430 & 400 \\
\hline
\end{tabular}

As shown in [24], thermoelastic dissipation is generally not significant for AlN micromechanical structures excited in contour mode shapes, and Q should be limited to approximately 32000 at frequencies approaching $1 \mathrm{GHz}$. This value is well beyond what is experimentally recorded. Thermoelastic damping is the loss of energy through dissipative thermal currents, which are induced by mechanical strains. Because the structure undergoes very small displacement and very small strain gradients by moving only in its plane, thermoelastic damping is not the dominant loss mechanism. This statement should be reviewed when the motion of the structure deviates from the ideal behavior and does not show a perfectly planar displacement. As is evident from the ANSYS simulation of Fig. 14 and the initial atomic force microscopy (AFM) measurements [30], the motion of a circular ring deviates from the ideal planar motion. The asymmetry introduced by the different metal electrodes that were used and the sloped sidewalls of the device produce out-of-plane deflections as seen in Figs. 14 and 15.

Also, out-of-plane deflections could play an important role in affecting anchor losses [31]. Mechanical vibrations induced at the anchoring points cause mechanical energy to escape the system, unless some techniques that make use of quarter-wave reflectors are adopted in order to trap the energy inside the microstructure [32]. The quarter-wave supports work efficiently only if the vibrations are confined in the plane of the structure.

Experimental studies have been conducted on one-port circular rings and rectangular plates in order to identify the effect of anchor losses on the overall quality factor. The experimental 
TABLE IV

EXPerimental Results in Terms of Center Frequency, Q, AND Motional Resistance For a $200 \times 50 \mu$ m Plate ExCited in Length-Extensional (Subscript 1) AND Width-Extensional (Subscript 2) Mode Shapes For Which ANCHOR Location (Fig. 16) AND Size Were Changed. The Data ARE FOR RESONATORS FABRICATED ON THE SAME WAFER

\begin{tabular}{|c|c|c|c|c|c|c|}
\hline $\mathbf{L}[\mu \mathrm{m}] \mathrm{x} \quad \mathrm{W}[\mu \mathrm{m}]) \mid$ Type & $\mathbf{f}_{1}[\mathrm{MHz}]$ & $\mathbf{Q}_{1}$ & $\mathbf{R}_{\mathrm{M} 1}[\mathbf{\Omega}]$ & $\mathrm{f}_{2}[\mathrm{MHz}]$ & $\mathbf{Q}_{2}$ & $\mathbf{R}_{\mathrm{M} 2}[\mathbf{\Omega}]$ \\
\hline $\begin{array}{l}25 \times 6 \mid A \\
\end{array}$ & 19.82 & 2200 & 760 & 84.8 & 670 & 380 \\
\hline $25 \times 10 \mid \mathrm{A}$ & 19.98 & 2200 & 800 & 85.3 & 1500 & 190 \\
\hline \begin{tabular}{l|l}
$50 \times 6$ & $A$
\end{tabular} & 19.93 & 2200 & 800 & 85.2 & 250 & 640 \\
\hline $\begin{array}{l}50 \times 10 \mid A \\
\end{array}$ & 19.93 & 2500 & 680 & 85.2 & 250 & 670 \\
\hline $\begin{array}{l}12.5 \times 6 \mid \mathrm{A} \\
\end{array}$ & 19.81 & 2200 & 770 & 87.0 & 1800 & 210 \\
\hline \begin{tabular}{ll|l}
$12.5 \times 6$ & $\mathrm{~A}$ \\
\end{tabular} & 19.82 & 1600 & 980 & 87.0 & 700 & 420 \\
\hline $25 \times 6 \mid \mathrm{B}$ & 19.96 & 2500 & 700 & 85.4 & 2200 & 125 \\
\hline \begin{tabular}{l|l|l}
$25 \times 10$ & $B$ \\
\end{tabular} & 19.97 & 1700 & 980 & 85.4 & 1700 & 170 \\
\hline $\begin{array}{l}50 \times 6 \mid \mathrm{B} \\
\end{array}$ & 19.91 & 2700 & 650 & 85.3 & 1200 & 230 \\
\hline $\begin{array}{l}50 \times 10 \mid B \\
\end{array}$ & 19.94 & 2100 & 800 & 85.4 & 1300 & 220 \\
\hline \begin{tabular}{ll|l}
$12.5 \times 6$ & $\mathrm{~B}$
\end{tabular} & 19.83 & 1900 & 870 & 87.2 & 770 & 310 \\
\hline \begin{tabular}{ll|l}
$12.5 \times 6$ & $\mathrm{~B}$ \\
\end{tabular} & 19.87 & 1300 & 1200 & 87.1 & 540 & 420 \\
\hline $25 \times 6 \mid C$ & - & - & - & 85.2 & 1460 & 190 \\
\hline $25 \times 10 \mid C$ & - & - & - & 85.2 & 400 & 600 \\
\hline $50 \times 6 \mid C$ & - & - & - & 85.3 & 1400 & 200 \\
\hline $50 \times 10 \mid C$ & - & - & - & 85.2 & 250 & 700 \\
\hline $12.5 \times 6 \mid \mathrm{C}$ & - & - & - & 85.3 & 2150 & 130 \\
\hline $12.5 \times 6 \mid \mathrm{C}$ & - & - & - & 85.4 & 1100 & 230 \\
\hline $25 \times 6 \mid D$ & - & - & - & 85.3 & 1500 & 180 \\
\hline $25 \times 10 \mid \mathrm{D}$ & - & - & - & 85.4 & 940 & 280 \\
\hline $50 \times 6 \mid \mathrm{D}$ & - & - & - & 85.3 & 2100 & 130 \\
\hline $50 \times 10 \mid \mathrm{D}$ & - & - & - & 85.6 & 1800 & 150 \\
\hline $12.5 \times 6 \mid \mathrm{D}$ & - & - & - & 85.3 & 2900 & 90 \\
\hline $12.5 \times 6 \mid \mathrm{D}$ & - & - & - & 85.6 & 2100 & 130 \\
\hline
\end{tabular}

results have shown that the number of anchors drastically affect the mode shape of circular rings. The use of two tethers, unless notched, gives rise to unwanted modes and degrades the quality factor of the device. As shown by the experimental results presented in previous sections, notched supports minimize interferences of the anchors with respect to the mode shape but do not seem to directly affect the $\mathrm{Q}$ of the structure. From the results illustrated in Table III it is evident that the width of the anchor does not substantially affect the $\mathrm{Q}$ of the resonator for a fixed ring diameter size.

A different trend was observed for the rectangular plates. The use of two tethers renders the mode shape more stable (no spurious resonances are introduced) and the structure capable of withstanding higher power. In general, before they experience mechanical nonlinearity, $200 \times 50 \mu \mathrm{m}$ rectangular plate resonators can withstand power levels up to $-7 \mathrm{dBm}$ with two tethers and $-11 \mathrm{dBm}$ with one tether when excited in the width-extensional mode. Because smaller displacement and larger stiffness characterize the same resonators at higher frequency, it is expected that these resonators will be able to withstand larger power levels in the order of several $\mathrm{dBms}$ at gigahertz frequencies. This trend is confirmed by the circular rings that can withstand power levels between -5 and $-3 \mathrm{dBm}$ at $230 \mathrm{MHz}$. In addition, for the plates, the width and length of the tethers do affect Q. In general, shorter and thinner tethers improve the quality factor of the resonator (Table IV). It is also important to note that by changing the clamping location (Fig. 16) and moving the anchors from along the length (Type $\mathrm{A}$ and $\mathrm{B}$ ) of the structure to along its width (Type C and D), the

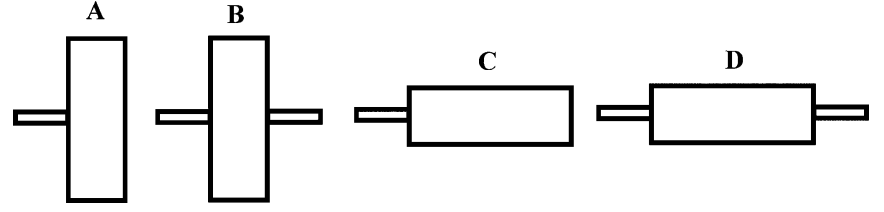

Fig. 16. Schematic representation of different anchoring schemes used on rectangular plate resonators.

length-extensional mode is suppressed. Although quarter-wave tethers were implemented for both types of resonators, they do not seem to play a significant role in minimizing energy loss. The undercut produced by the release process affects the support length and stiffness, making it difficult to establish whether the tethers are effectively behaving as quarter-wave reflectors. A more efficient way of building reflectors is to introduce a material mismatch between the mechanical structure and the anchors [10].

Air damping is not a dominant loss mechanism for contourmode resonators. Experiments in vacuum and at atmospheric pressure have shown Q improvements in vacuum of $20-30 \%$ for rectangular plates below $100 \mathrm{MHz}$ and of approximately $14 \%$ for circular ring at $230 \mathrm{MHz}$. It is believed that the effect of air damping will decrease at higher frequencies because the resonator displacement diminishes with frequency.

Electric losses introduced by metal lines with relatively high resistivity such as $\mathrm{Pt}$ (Pt resistivity is about four times that of $\mathrm{Al})$ can become significant especially if the motional resistance 


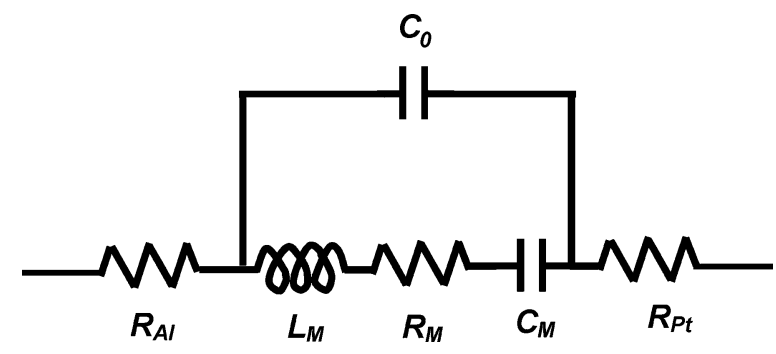

Fig. 17. Augmented BVD model including electrical losses in the $\mathrm{Al}\left(\mathrm{R}_{\mathrm{Al}}\right)$ and $\left(\mathrm{Pt} \mathrm{R}_{\mathrm{Pt}}\right)$ electrodes.

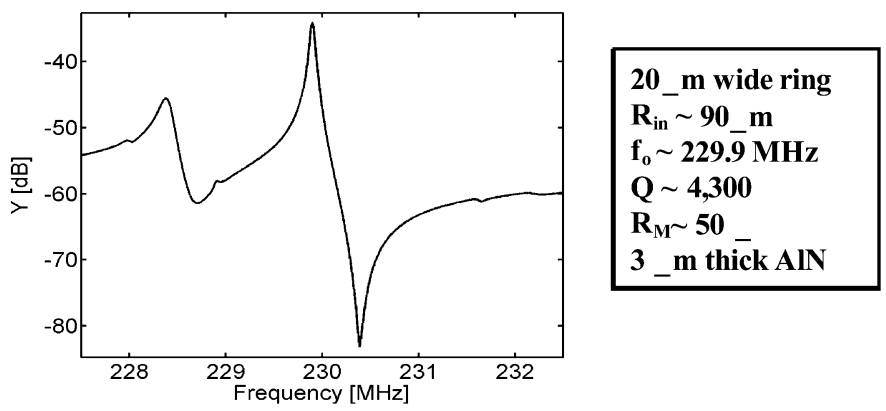

Fig. 18. Admittance plot for a $20 \mu \mathrm{m}$ circular ring resonator showing $\mathrm{Q}$ of 4300 at 229.9 MHz. This resonator was made out of $3-\mu \mathrm{m}$-thick AlN.

of the resonators keeps decreasing. Currently, ring-shaped resonators with Pt thickness of around $100 \mathrm{~nm}$ do not exhibit Qs higher than 2000, whereas devices with Pt thickness of about $200 \mathrm{~nm}$ were able to reach quality factors as high as 3000 . Either thicker electrodes or lower resistivity metals will be required when the $\mathrm{Q}$ is raised and the motional resistance of the microresonator is reduced. The losses introduced by the series resistance due to the metal electrodes should therefore be taken into account in the equivalent electrical model and the simple Butterworth Van Dyke (BVD) model modified as shown in Fig. 17. These electrical losses were not included in the calculations of the equivalent electrical parameters of the resonators reported in Table I. Their effect cannot in fact be described by a simple model, but a distributed model that takes into account the fact that the resonator is locally in parallel with the electrode at each point on its surface should be adopted. Efforts to characterize this effect are ongoing.

Another interesting result that can be linked to losses due to electrical resistivity, but cannot solely be explained by it, is the experimental observation that higher quality factors (as high as 4300 ) were obtained for 3 - $\mu \mathrm{m}$-thick circular ring microresonators (Fig. 18). Thicker resonators have slightly larger motional resistance $\left(\mathrm{R}_{\mathrm{M}}\right.$ is proportional to film thickness) and are therefore less sensitive to ohmic electrical loading. At the same time the higher $\mathrm{Q}$ could be related to the larger volume of the structure. It has in fact been shown that $\mathrm{Q}$ tends to increase with volume [33].

Finally, material losses could play an extremely important role. Whereas it is believed that AlN is a high Q material, the metal electrodes might be a primary source of energy loss. It has been shown in the literature [34], [35] that metals generally have low Q and could dramatically affect the overall Q of the resonator. Although this statement is purely speculative and has not been proven experimentally for contour-mode resonators, the authors strongly believe that the internal mechanical losses in the electrodes could be one of the primary reasons of $Q$ degradation.

\section{CONCLUSION}

For the first time, low motional resistance plate and ringshaped contour-mode AlN piezoelectric resonators were successfully demonstrated. These resonators exhibit Q as high as 4300 at $230 \mathrm{MHz}$ in air and small impedance values that permit their interface with $50 \Omega \mathrm{RF}$ systems. The center frequency of these piezoelectric resonators is set by lithographic techniques (and not film thickness as for FBARs or shear quartz resonators), therefore truly enabling the fabrication of arrays of microresonators with different frequencies on a single chip. Initial theoretical and experimental observations were provided to describe mass loading, temperature effects, and energy loss mechanisms for this new class of MEMS resonators. Based on the reported results, circular ring resonators and rectangular plate resonators can be considered as the optimal candidates to demonstrate high-Q and high-frequency resonators. Arrangements of parallel arrays of small resonators may be required to maintain overall structural stiffness and low motional resistance at high frequency. Ongoing research focuses its attention on expanding the frequency range of these resonators to gigahertz, increasing their $\mathrm{Q}$ factor and eliminating spurious responses.

\section{ACKNOWLEDGMENT}

The authors wish to thank AMS Inc. for help with the deposition of AlN films and tool installation and the Microfabrication Laboratory staff at the University of California, Berkeley, for their help.

\section{REFERENCES}

[1] W. Jing, Z. Ren, and C.-C. Nguyen, "1.156-GHz self-aligned vibrating micromechanical disk resonator," IEEE Trans. Ultrason. Ferroelectr. Freq. Control, vol. 51, pp. 1607-1628, 2004.

[2] H. Takeuchi, E. Quevy, S. A. Bhave, K. Tsu-Jae, and R. T. Howe, "Ge-blade damascene process for post-CMOS integration of nano-mechanical resonators," IEEE Electron Device Lett., vol. 25, pp. 529-531, 2004.

[3] S. Pourkamali, G. K. Ho, and F. Ayazi, "Vertical capacitive SiBARs," in 18th IEEE Int. Conf. Micro Electro Mechanical Syst. (MEMS 2005), 2005, pp. 211-214.

[4] W. Jing, J. E. Butler, T. Feygelson, and C.-C. Nguyen, "1.51-GHz nanocrystalline diamond micromechanical disk resonator with material-mismatched isolating support," in 17th IEEE Int. Conf. Micro Electro Mechanical Syst. (MEMS 2004), 2004, pp. 641-644.

[5] B. Bircumshaw, G. Liu, H. Takeuchi, K. Tsu-Jae, R. Howe, O. O'Reilly, and A. Pisano, "The radial bulk annular resonator: Towards a 50 Omega RF MEMS filter," in Proc. 12th Int. Conf. Solid-State Sens., Actuators Microsyst. (TRANSDUCERS '03), 2003, vol. 1, pp. 875-878

[6] G. K. Ho, K. Sundaresan, S. Pourkamali, and F. Ayazi, "Low-motionalimpedance highly-tunable I/sup 2/resonators for temperature-compensated reference oscillators," in Proc. 18th IEEE Int. Conf. Micro Electro Mechanical Syst. (MEMS 2005), 2005, pp. 116-120.

[7] S. Pourkamali and F. Ayazi, "High frequency capacitive micromechanical resonators with reduced motional resistance using the HARPSS technology," in Proc. 2004 Topical Meeting Silicon Monolithic Integrated Circuits RF Syst., 2004, pp. 147-150.

[8] L. Sheng-Shian, L. Yu-Wei, X. Yuan, R. Zeying, and C.-C. Nguyen, "Micromechanical "hollow-disk" ring resonators," in 17th IEEE Int. Conf. Micro Electro Mechanical Syst. (MEMS 2004), 2004, pp. $821-824$. 
[9] S. A. Bhave and R. T. Howe, "Internal electrostatic transduction for bulk MEMS resonators," in Proc. 2004 Solid State Sens., Actuator Microsyst. Workshop, Hilton Head Island, SC, 2004, pp. 59-60.

[10] _ " "Silicon nitride-on-silicon bar resonator using internal electrostatic transduction," in Proc. Solid-State Sens., Actuators Microsyst. (TRANSDUCERS '05), 2005, pp. 2139-2142.

[11] D. Penunuri and K. M. Lakin, "RF filter design using LTCC and thin film BAW technology," in Proc. 2001 IEEE Ultrason. Symp., 2001, vol. 1, pp. 273-278.

[12] R. Ruby, P. Bradley, J. D. Larson, III, and Y. Oshmyansky, "PCS 1900 MHz duplexer using thin film bulk acoustic resonators (FBARs)," Electron. Lett., vol. 35, pp. 794-795, 1999.

[13] F. P. S. D. T. Chang, D. J. Kirby, R. J. Joyce, T.-Y. Hsu, and R. L. Kubena, "A new MEMS-based quartz resonator technology," in Proc. Solid State Sens., Actuator Microsyst. Workshop, Hilton Head Island, SC, 2004, pp. 41-44.

[14] R. A. Johnson, Mechanical Filters in Electronics. New York: Wiley, 1983.

[15] R. Holland, "Contour extensional resonant properties of rectangular piezoelectric plates," IEEE Trans. Sonics Ultrason., vol. SU-15, pp. 97-105, 1968.

[16] M. Onoe, "Contour vibrations of thin rectangular plates," J. Acoust. Soc. Amer., vol. 30, pp. 1159-1162, 1958.

[17] G. Ambati, J. F. W. Bell, and J. C. K. Sharp, "In-plane vibrations of annular rings," J. Sound Vibrations, vol. 47, pp. 415-432, 1976.

[18] K. F. Graff, Wave Motion in Elastic Solids. New York: Dover, 1991.

[19] G. Piazza, P. J. Stephanou, M. B. J. Wijesundara, and A. P. Pisano, "Single-chip multiple-frequency filters based on contour-mode aluminum nitride piezoelectric micromechanical resonators," in Proc. Solid-State Sens., Actuators Microsyst. (TRANSDUCERS '05), 2005, pp. 2065-2068.

[20] E. P. Quevy and R. T. Howe, "Redundant MEMS resonators for precise reference oscillators," in Proc. Radio Frequency Integrated Circuits (RFIC) Symp., 2005, pp. 113-116.

[21] G. Bu, D. Ciplys, M. Shur, L. J. Schowalter, S. Schujman, and R. Gaska, "Temperature coefficient of SAW frequency in single crystal bulk AlN," Electron. Lett., pp. 755-757, 2003.

[22] P. Wei, Y. Hongyu, Z. Hao, and E. S. Kim, "Temperature-compensated film bulk acoustic resonator above $2 \mathrm{GHz}$," IEEE Electron Device Lett., pp. 369-371, 2005.

[23] H. Wan-Thai, J. R. Clark, and C.-C. Nguyen, "Mechanically temperature-compensated flexural-mode micromechanical resonators," in Proc. Int. Electron Devices Meeting (IEDM 2000), 2000, pp. 399-402.

[24] B. Antkowiak, J. P. Gorman, M. Varghese, D. J. D. Carter, and A. E. Duwel, "Design of a high-Q, low-impedance, GHz-range piezoelectric mems resonator," in Proc. 12th Int. Conf. Solid-State Sens., Actuators Microsyst. (TRANSDUCERS '03), 2003, vol. 1, pp. 841-846.

[25] R. Abdolvand, G. K. Ho, A. Erbil, and F. Ayazi, "Thermoelastic damping in trench-refilled polysilicon resonators," in Proc. 12th Int. Conf. Solid-State Sens., Actuators Microsyst. (TRANSDUCERS '03), 2003, vol. 1, pp. 324-327.

[26] R. N. Candler, H. Li, M. Lutz, W. T. Park, A. Partridge, G. Yama, and T. W. Kenny, "Investigation of energy loss mechanisms in micromechanical resonators," in Proc. 12th Int. Conf. Solid-State Sens., Actuators Microsyst. (TRANSDUCERS '03), 2003, vol. 1, pp. 332-335.

[27] V. T. Srikar and S. D. Senturia, "Thermoelastic damping in fine-grained polysilicon flexural beam resonators," J. Microelectromech. Syst., pp. 499-504, 2002.

[28] X. M. H. Huang, C. A. Zorman, M. Mehregany, and M. L. Roukes, "Quality factor issues in silicon carbide nanomechanical resonators," in Proc. 12th Int. Conf. Solid-State Sens., Actuators Microsyst. (TRANSDUCERS '03), 2003, vol. 1, pp. 722-725.

[29] R. C. Ruby, J. D. Larson, R. S. Fazzio, and C. Feng, "Performance degradation effects in FBAR filters and resonators due to lamb wave modes," in 2005 IEEE Ultrason. Symp., 2005, pp. 1832-1835.

[30] X. Liu, A. San Paulo, M. Park, and J. Bokor, "Characterization of acoustic vibration modes at $\mathrm{GHz}$ frequencies in bulk acoustic wave resonators by combination of scanning laser interferometry and scanning acoustic force microscopy," in Proc. 18th IEEE Int. Conf. Micro Electro Mechanical Syst. (MEMS 2005), 2005, pp. 175-178.
[31] D. S. Binder, E. Quevy, T. Koyama, S. Govindjee, J. W. Demmel, and R. T. Howe, "Anchor loss simulation in resonators," in Proc. 18th IEEE Int. Conf. Micro Electro Mechanical Syst. (MEMS 2005), 2005, pp. 133-136.

[32] K. M. Lakin, K. T. McCarron, and R. E. Rose, "Solidly mounted resonators and filters," in Proc. 1995 IEEE Ultrason. Symp., 1995, vol. 2, pp. 905-908.

[33] K. L. Ekinci and M. L. Roukes, "Nanoelectromechanical systems," Rev. Sci. Instrum., vol. 76, pp. 61101-1-61101-12, 2005.

[34] R. Lanz, M. A. Dubois, and P. Muralt, "Solidly mounted BAW filters for the 6 to $8 \mathrm{GHz}$ range based on AlN," in 2001 IEEE Ultrason. Symp., 2001, vol. 1, pp. 843-846.

[35] C. G. Courcimault and M. G. Allen, "High-Q mechanical tuning of MEMS resonators using a metal deposition-annealing technique," in Proc. Solid-State Sens., Actuators Microsyst. (TRANSDUCERS '05), 2005, pp. 875-878.

[36] P. J. Stephanou, G. Piazza, C. D. White, M. B. J. Wijesundara, and A. P. Pisano, "Piezoelectric thin film AlN annular dual contour mode bandpass filter," in Proc. ASME IMECE 2005, 2005.

Gianluca Piazza (S'00-M'06) received the Ph.D. degree from the University of California, Berkeley, in 2005.

$\mathrm{He}$ is an Assistant Professor in the Department of Electrical and Systems Engineering, the University of Pennsylvania, Philadelphia. His research interests focus on piezoelectric micro and nano systems (MEMS/NEMS) for RF wireless communications, biological detection, and wireless sensor platforms. He also has general interest in the areas of micro/nanofabrication techniques and integration of micro/nanodevices with state-of-the-art electronics. He developed a new class of AlN contour-mode vibrating microstructures for RF communications. He has more than six years of experience working with piezoelectric materials, has received two patents in the field of micromechanical resonators, and cofounded a startup company (Harmonic Devices, Inc.) for the commercialization of piezoelectric resonators.

Philip J. Stephanou (M'05) received the B.S. and M.S. degrees from Rensselaer Polytechnic Institute, Troy, NY, in 2001 and 2002, respectively. He is currently pursuing the Ph.D. degree at the Mechanical Engineering Department, University of California, Berkeley.

His thesis investigated the performance of novel algorithms for computational multi-rigid-body dynamics. His current research involves the analysis, design and fabrication of piezoelectric RF MEMS resonators and filters for highly integrated communication systems. In spring 2005, he cofounded Harmonic Devices, Inc., a fabless semiconductor startup company committed to commercializing research breakthroughs in the area of RF MEMS for the mobile handset market. He is currently the acting Chief Technology Officer.

Albert ("Al”) P. Pisano received the B.S., M.S., and Ph.D. degrees in mechanical engineering from Columbia University, New York, NY.

He currently is Professor and Chair of the Department of Mechanical Engineering, University of California (UC), Berkeley, where he holds the FANUC Chair of Mechanical Systems in the Department of Mechanical Engineering, with a joint appointment to the Department of Electrical Engineering and Computer Science. He currently is a Director of the Berkeley Sensor and Actuator Center (BSAC). Prior to joining UC Berkeley, he held research positions with Xerox Palo Alto Research Center, Singer Sewing Machines Corporate R\&D Center, and General Motors Research Labs. From 1997 to 1999, he was Program Manager for the MEMS program at the Defense Advanced Research Projects Agency. His research interests and activities at UC Berkeley include MEMS for a wide variety of applications, including RF components, power generation, drug delivery, strain sensors, biosensors and disk-drive actuators. He is the Coinventor listed on 20 patents in MEMS. He has authored or coauthored more than 190 archival publications. He is a Cofounder of startup companies in the area of transdermal drug delivery, transvascular drug delivery, sensorized catheters, MEMS manufacturing equipment, and MEMS RF devices.

Prof. Pisano was elected to the National Academy of Engineering in 2001. 